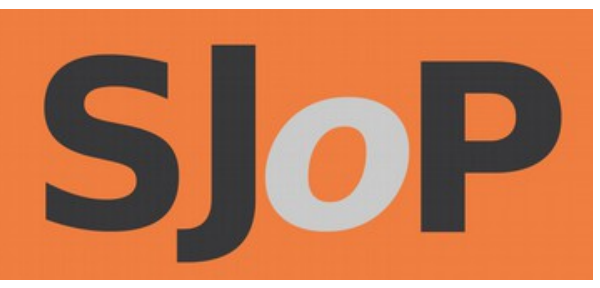

\title{
Relaxed performance: audiences with autism in mainstream theatre
}

\section{BEN FLETCHER-WATSON}

The Scottish Journal of Performance

Volume 2, Issue 2; June 2015

ISSN: 2054-1953 (Print) / ISSN: 2054-1961 (Online)

Publication details: http://www.scottishjournalofperformance.org

To cite this article: Fletcher-Watson, B., 2015. Relaxed performance: audiences with autism in mainstream theatre. Scottish Journal of

Performance, 2(2): pp.61-89.

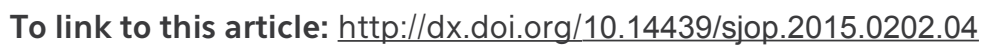

CC 1 This work is licensed under a Creative Commons
Attribution 4.0 International License. See
http://creativecommons.org/licenses/by/4.0/ for details. 


\title{
Relaxed performance: audiences with autism in mainstream theatre
}

\author{
BEN FLETCHER-WATSON
}

DOI: 10.14439/sjop.2015.0202.04

Publication date: 26 June 2015

Emerging less than a decade ago, 'relaxed performances' now take place at many theatres in the UK and USA. These events encourage attendance at mainstream productions by hitherto neglected audiences, particularly those with autism. The changes made may include reduced intensity of lighting and sound, the provision of visual stories to familiarise theatregoers with the venue and production, and trained staff on hand to assist visitors.

This paper examines the rise in relaxed performance since 2009, providing a synopsis of current practice. A short case study of a relaxed performance of The Lion King then prompts three questions: what do autistic theatregoers want from a theatre performance? Do relaxed performances alter the conventions of live theatre? What is their impact on actors?

The paper also considers the role of human rights in inclusive arts, and proposes several avenues for future research into this challenging and exciting movement.

Keywords: relaxed performance, autism, theatre, autismfriendly, The Lion King 


\section{Introduction}

In recent years, theatres around the world have begun to embrace new means of accommodating audiences previously neglected by theatre makers. Performances for babies and their carers are now increasingly common in Europe and the USA (Fletcher-Watson et al., 2014), along with productions designed to engage people with dementia, profound multiple learning difficulties (PMLD) and those on the autism spectrum (Brown, 2012). Performances may reduce audience size to ensure comfort and engagement (Belloli, Morris and Phinney, 2013), provide participatory experiences such as communal eating or dance (Nerattini, 2009), employ kinaesthetic and other sensory stimuli (Brown, 2012), and tour to non-theatrical venues, including special schools, care homes and nurseries. When creating such pieces, artists tend to draw on theoretical frameworks from psychology, pedagogy, dramatherapy and medicine, in addition to conventional dramaturgical modes.

Similarly, theatre is regularly employed as a therapeutic intervention for a variety of groups, such as people with intellectual disabilities (Sherratt and Peter, 2002; Ramamoorthi and Nelson, 2011; Godfrey and Haythorne, 2013; Lewis and Banerjee, 2013; Corbett et al., 2014). Artists and therapists use drama exercises with participants to develop their social or emotional skills, although the resulting work is very rarely presented in a professional context (Hall, 2010). Both theatre for and by these neglected audiences is, to an extent, therefore excluded from the sites where performances are traditionally presented-the theatre itself.

Indeed, it has long been recognised that 'mainstream theatre fails to fulfil the needs of some spectators in our society' (Lancaster, 1997, p.75). Therefore, a parallel third movement of inclusion aims to encourage attendance at mainstream productions by audiences disadvantaged by 
various factors, including disability (for example, via the provision of a T-loop or hearing aid loop for D/deaf patrons, and touch tours of the set for partially-sighted visitors), income (as at 'Pay What You Can' performances) or inexperience (through audience development and outreach activities).

However, for audience members with intellectual disabilities and those on the autism spectrum ${ }^{1}$, access to mainstream theatre has traditionally been severely limited, often due to concerns about potential disruption for other theatregoers (see, for example Elkin, 2015). A 2002 survey found that $68 \%$ of children with disabilities did not engage with play and leisure providers due to being 'made to feel uncomfortable' (quoted in Broach et al., 2003, p.22). In an effort to accommodate these disadvantaged groups ${ }^{2}$, occasional performances within longer runs have begun to be tailored to their specific needs. Originally known as autism-friendly or sensory-friendly performances, such events are now generally described as relaxed performances (RPs), reflecting perhaps a growing recognition of their appeal to a wider constituency than solely autistic people and their families. The term 'relaxed' remains contested, with alternatives proposed including 'extra-live' (Thom, 2015) and, more provocatively, 'not uptight' (Roundhouse, 2015), mirroring Rosemarie Garland Thomson's binary coinages of 'extraordinary' and 'normate' to describe bodies in society (1997). As the term used most widely in current marketing materials from venues, 'relaxed performance' is the preferred term in this paper.

RPs became a part of inclusive practice in 2009, with the first autism-friendly performances taking place at Polka Theatre in London. Other pioneers included West Yorkshire Playhouse in Leeds, as well as London's Little Angel Theatre and Unicorn Theatre. The Relaxed Performance Project in 2012 and 2013-organised by the Ambassador Theatre 
Group, Prince's Foundation for Children and the Arts, the Society of London Theatres and the Theatrical Management Association-has been highlighted as the tipping point (Kempe, 2014), although it is important to note that this emerged from an 'Industry Inspiration Day' held on 10 October 2011 at the Unicorn Theatre (http://www.uktheatre.org, 2011). The project saw large cultural organisations such as the Royal Shakespeare Company and National Theatre work alongside West End venues and regional theatres to produce a series of RPs directed at children and young people.

In the USA, a similar genealogy can be traced, with RPs staged from 2011 at regional venues specialising in children's theatre such as Adventure Theatre in Maryland and Paper Mill Playhouse in New Jersey. In October of that year, the first Broadway RP was presented at New York's Minskoff Theatre, for Disney's The Lion King.

The number of RPs has risen sharply since then, despite claims that they are still 'few and far between' (Heaton, 2013, p.2). In 2014 in particular, UK pantomimes increasingly began to offer RPs, with at least 48 staged during the 201415 season. As Kempe has noted, 'for many children their first and often only experience of live theatre is the annual pantomime. To exclude families living with autism from this is tantamount to excluding them from a part of their local community and national cultural heritage' (2014, p.263).

\section{Autism and theatre}

Autism is mostly known for a characteristic and unusual style of social interaction (Frith, 2003), but a need for routine and predictability, and unusual reactions to sensory input are also features of the diagnosis (Wing and Gould, 
1979). Some, but not all, people with autism also have an intellectual disability (ID). For autistic audience members with or without ID, crowds of people, loud noises, unfamiliar spaces and dimmed lighting can conspire to produce a profoundly unsettling atmosphere. In addition, some theatres still do not actively welcome patrons who require accommodations to enjoy a performance, seeing them perhaps as outside their desired audience, or part of outreach activity rather than customers.

Typically, a relaxed performance attempts to accommodate numerous common features of autism to create a safe, nonjudgmental atmosphere where the autistic theatregoer can relax and enjoy live performance:

\begin{tabular}{|l|l|}
\hline Feature of autism & Accommodation in relaxed performance \\
\hline Insistence on & $\begin{array}{l}\text { Social stories (also called visual stories)-these } \\
\text { documents, circulated in advance, can be brief character } \\
\text { guides or song lists, or longer documents with } \\
\text { photographs of the theatre, accompanying Makaton } \\
\text { symbols }\end{array}$ \\
$\begin{array}{l}\text { IDs) and a description of what will happen from when } \\
\text { they enter the venue to when the show ends. Some } \\
\text { venues provide a separate 'list of surprises', allowing } \\
\text { carers to choose whether to share these. }\end{array}$ \\
\hline $\begin{array}{l}\text { Hypersensitivities/ } / \text { 'Meet Your Seat!': a free Open House on a day prior to } \\
\text { herformance expressly for children to become familiar } \\
\text { with the space and grounds and to ease their transition. }\end{array}$ \\
$\begin{array}{l}\text { A short welcome/introduction to the stage: some venues } \\
\text { choose to demonstrate surprises which will appear, such } \\
\text { as trapdoors or flown scenery, in order to let } \\
\text { theatregoers prepare. }\end{array}$ \\
\hline $\begin{array}{l}\text { House lights kept on. } \\
\text { Signallers with glow sticks or flash cards on either side } \\
\text { of the stage to warn theatregoers of upcoming loud }\end{array}$ \\
\hline
\end{tabular}




\begin{tabular}{|l|l|}
\hline & $\begin{array}{l}\text { noises, or to signal that clapping will occur. } \\
\text { Coloured cards to hold up to signal a willingness to } \\
\text { engage in interaction with performers. }\end{array}$ \\
\hline $\begin{array}{l}\text { Small changes to the production, including reducing } \\
\text { intense special effects, lowering the tap sounds of dance } \\
\text { routines, softening transitions and lowering the pitch of } \\
\text { some songs. }\end{array}$ \\
\hline $\begin{array}{l}\text { High incidence of } \\
\text { epilepsy }\end{array}$ & $\begin{array}{l}\text { Removing strobe lights (a potential trigger for photo- } \\
\text { sensitive epilepsy). }\end{array}$ \\
\hline $\begin{array}{l}\text { High incidence of } \\
\text { anxiety }\end{array}$ & $\begin{array}{l}\text { Calm spaces/activity areas in the lobby, where children } \\
\text { can watch a live stream of the show if they need to leave } \\
\text { the auditorium; colouring books, puzzles, games and } \\
\text { quiet toys for use as needed. }\end{array}$ \\
\hline $\begin{array}{l}\text { Lack of } \\
\text { understanding of } \\
\text { general public }\end{array}$ & $\begin{array}{l}\text { Training for frontline staff, and the presence of trained } \\
\text { helpers in the theatre and lobby, providing assistance to } \\
\text { families-these may be local students, special education } \\
\text { experts, social workers or ushers with an interest in } \\
\text { inclusive arts. }\end{array}$ \\
\hline
\end{tabular}

Figure 1: table outlining various inclusive measures employed for relaxed performances. (Synthesised from Fletcher-Watson and Fletcher-Watson, 2013; Andrews and Begley, 2014; Kempe, 2014; Stone, 2014; Kempe, 2015)

Other measures not necessarily linked specifically to autism include:

- $\quad$ reduced ticket prices, reflecting the need for carers to accompany audience members

- 'buggy parking' in the lobby for walking frames and strollers

- free handouts or downloadable activity sheets to continue to explore the world of the production at home or school (Fletcher-Watson and FletcherWatson, 2013) 
In the UK, many of these measures connect to the National Autistic Society's SPELL framework for understanding and responding to the needs of people on the autism spectrum (Beadle-Brown, Roberts and Mills, 2009; Beadle-Brown and Mills, 2010). SPELL stands for: Structure (to promote independence through predictability); Positive (approaches and expectations should be positive to encourage exploration of new areas); Empathy (from those who interact with the autism community); Low arousal (to minimise distraction); and Links (between people with autism and their carers, parents, teachers, advocates and others).

\section{The rise in relaxed performance}

While the increase in availability of RPs has been reported widely in the media (Booth, 2013; Rubin, 2013, Stern, 2013; Carey, 2014; Didcock, 2014; Elkin, 2014; Merrill, 2014; Costa, 2015; Gallagher, 2015; Halpern, 2015; Viswanathan, 2015; Wise, 2015), few reliable or comprehensive records exist. A database of over 300 relaxed performances was therefore constructed using Google searches in English, covering variations on 'relaxed performance', 'sensory-friendly' and 'autism-friendly', in conjunction with citation searches and listings from major international festivals ${ }^{4}$. The following data were gathered for each performance: title, genre, venue, city, country and date. Where a production provided several RPs as part of a run, such as The Lion King at New York's Minskoff Theatre, each performance was listed separately.

The database shows a steep rise in RPs around the world from 2009 (the earliest identified relaxed performance) to 2015. Figure 2 provides a visualisation of these data, moving from a handful of performances in 2009 and 2010 to over 120 separate events in 2014. By December 2014, more than 
90 RPs had already been announced for the coming year.

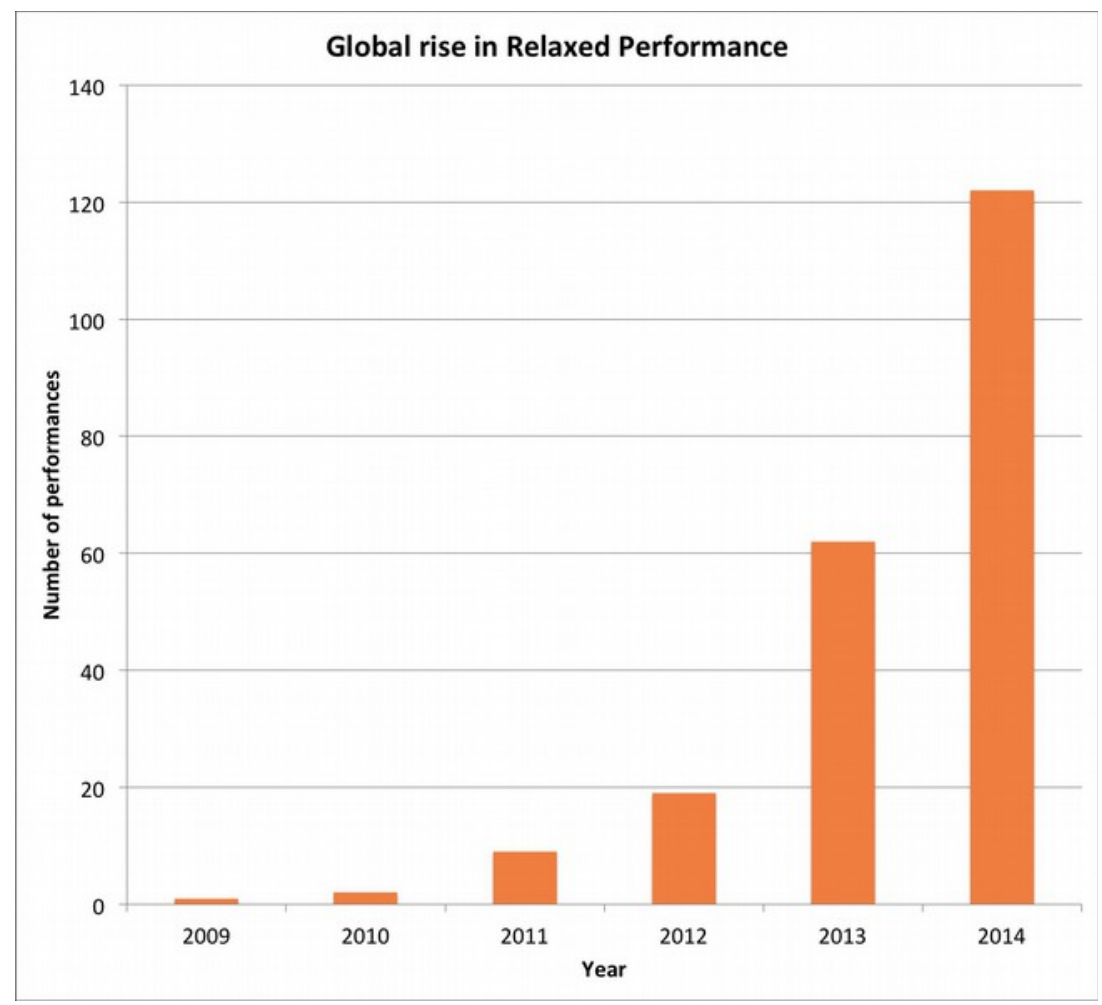

Figure 2: Global rise in relaxed performance, 2009-2014.

Children's productions represent the majority of RPs, making up $54 \%$ of the total. A considerable number of productions (22\%) are pantomimes, despite a claim by the Relaxed Performance Project that pantomime may be more challenging than traditional productions (Ambassador Theatre Group et al., 2013), although other studies have noted that some theatregoers with autism may in fact enjoy a highly stimulating environment, and be disappointed if explosions and other visual effects are reduced (Kempe, 2014). Musicals make up another 15\%. Only a small proportion of performances (8\%) derive from adult texts such as Shakespeare or contemporary drama. There is therefore currently a lack of provision for adults with autism and others who may wish to enjoy traditional drama but require a degree of accommodation in order to be able to visit the theatre. 


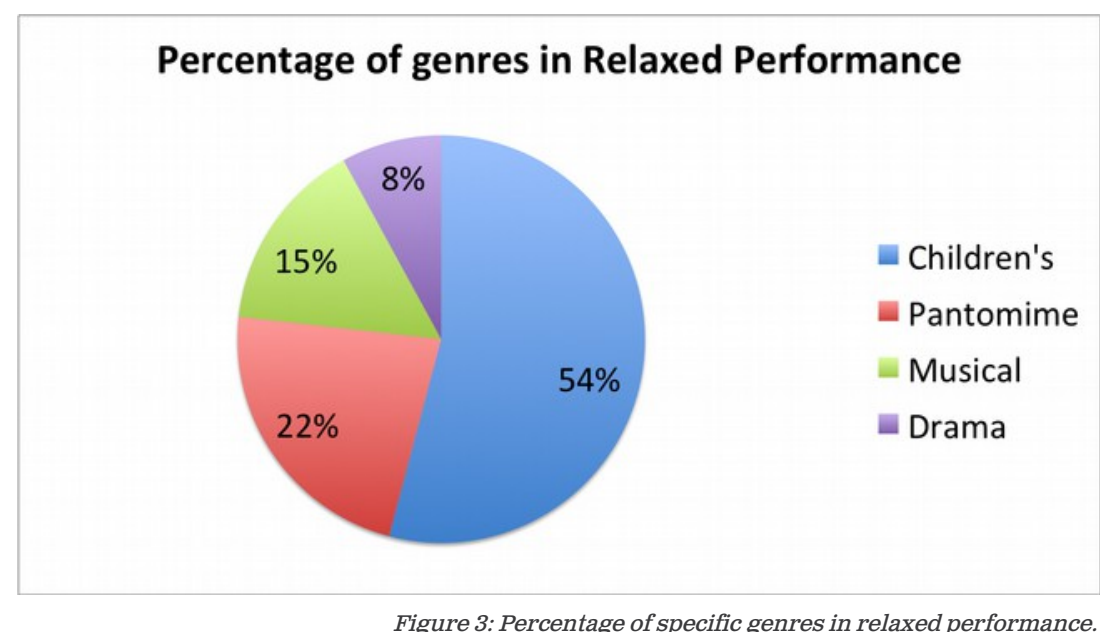

Figure 3: Percentage of specific genres in relaxed performance.

\section{Attending a relaxed performance: a case study}

On 24 November 2013, I attended a relaxed performance of Disney's The Lion King at the Edinburgh Playhouse with my 4-year-old daughter, who does not have autism. The following text is presented as an attempt to describe in detail the subjective experience of attending an RP, seeking to adopt and adapt Petra Kuppers's undertaking to focus 'not on art work created by people who live with diagnoses of autism, but on [performances] acted out, narrated, and danced by nondisabled people (who [may or may not] have significant experience of people who live with the diagnosis)' (2008, p.193). This lens seems particularly appropriate given the prevalence of nondisabled performers within RPs, permitting in particular the exploration of their experience or inexperience of playing to audiences with autism and the impacts this may have. Additionally, previous RP case studies (such as Kempe, 2014) have centred on production, rather than spectatorship.

We took our seats around 15 minutes before the show began, giving me time to settle and prepare my daughter for the performance, which would be the longest theatre experience she had attended to date. She put on her new 
pink ear-defenders, bought at her request as 'shows are too loud' and played games on an iPhone to while away the time. Looking around, other children were engaged in similar activities-sensory sensitivity means that many young people with autism choose to wear ear-defenders, and technology plays a significant role in their lives, from educational games to speech aids for non-verbal children.

My daughter did not stand out as an interloper at this event. The audience member to my left, accompanied by his partner and their son in his 20s, offered a booster seat. In his eyes, we were just another family attending the autismfriendly performance, which of course we were, but I was suddenly struck by the ethical murkiness of my 'undercover' visit. Of course, no-one would ask me about my daughter's diagnosis (or lack of one), but their expressions suggested that they had made an understandable assumption that she was a member of the autism community.

As we waited, I wondered about the extent to which autismfriendly performances might be forcing autistic people into a mainstream activity which they would not choose for themselves. What agency had been granted to the spectators around me to decide whether they wished to visit? Equally troublingly, should 'neurotypicals' ${ }^{5}$ like me and my daughter be allowed to go to such performances, taking up seats put aside for people who are normally not made welcome in the theatre? These thoughts are still a concern to me now.

The event began with a welcome from two performers in costume, Stephen Carlile, playing Scar, and Gugwana Dlamini, playing Rafiki. Carlile noted that the cast were 'honoured' to be performing today, pointed out the National Autistic Society volunteers around the auditorium, and stated that this was a special place-unlike the rest of the world, which expects people with autism to fit in with it, this 
theatre on this day was fitting in with autism. This generated a huge cheer from the audience. I know that there are strong feelings in the autism community that it is neurotypicals who need to learn the required skills to interact with autistic people, not vice versa, and the response to Carlile seemed to back this up.

The show then opened with Circle of Life and a parade of animals entering through the audience via both aisles. For a young boy next to us, an enormous elephant made up of four performers proved too much, and he asked to leave, but in the main, the audience responded as they would continue to respond for the remainder of the performance-loudly and joyfully.

Some effects seemed to have been muted slightly, such as the African drums set into balconies either side of the stage, but other effects were, perhaps unwisely, left intact. In particular, loud and sudden gas jets were set off in one scene, which caused many people around us to jump in surprise.

It was noticeable that the actors did not seem fazed by the unremitting noise and movement, which must have been louder and more obvious than in typical matinees. Audience members came and went as they wished, but I did not observe a single spectator object at having to let another theatregoer past. On the contrary, parents and carers exchanged smiles whenever this happened, and it is impossible to say whether this was out of sympathy, politeness or happiness at not being judged.

During the interval, groups of people quickly formed in the bar and lobby, excitedly discussing both the onstage action and their experiences in the auditorium. Quite a few people stayed in their seats and ate snacks or played on portable 
devices.

As the second half progressed, I noticed an increase in movement and noise from other audience members, perhaps suggesting a dissatisfaction with the length of time spent in the venue. People began to leave around ten minutes before the end of the show, either to avoid the rush later or because they had seen enough. We made our exit as the curtain call began. I noticed many people waving both hands above their heads in the BSL (British Sign Language) sign for 'applause'. Despite this, the clapping was tremendously loud!

Walking through the lobby, I noticed a large merchandising stand by the exit doors. For a moment, I was taken aback by the incursion of commercialism at this special event, but this could be considered part of the 'mainstreaming' of autism-friendly theatre: when people with autism are welcomed into venues, they become consumers as well as audiences.

\section{Discussion}

My experience at The Lion King prompted a series of questions which may trouble some of the assumptions prevalent in existing literature on theatre and autism.

- What does the autistic theatregoer want from a theatre performance, relaxed or otherwise?

- Is RP a discrete mode of performance, or is it simply an adaptation of theatre etiquette? How are the semiotics and conventions of live theatre affected by $\mathrm{RP}$ ? 
- Does the presence of autistic audiences impact on an actor's performance, and if so, how?

The first question concerns the often contradictory aims of stakeholders in accessible arts: for venues, RPs can offer an opportunity to engage with (and be seen to engage with) a previously neglected audience. The reduced income concomitant with RP is outweighed by benefits in areas such as media coverage, audience development, outreach and new skills for staff. For educators, RPs could be seen to have the potential to develop social skills in people with autism. For parents, they may provide the chance to enjoy time with their family and wider peer group in a non-judgmental space. For campaigners, 'the $R P$ can represent an opportunity to signal the presence and nature of autism to the wider community. By fostering greater understanding and acceptance, some of the tensions that can spark alarming behaviour may be alleviated' (Kempe, 2014, p.272).

Yet the voice of the autistic audience member is rarely heard in debates on social inclusion. Like the very young or the very old they are spoken for, and their cultural experiences can centre on being brought into the mainstream, rather than curating their own artistic engagement. This has been described as 'an assumption of the self as normative which informs ideas of inclusion, rather than [recognising] the focus in the legislation to enable participation in civic life and access to services' (Roberts, Beadle-Brown and Youell, 2011, p.49). Indeed, normative assumptions extend to a common belief that, like very young children, autistic people of all ages attend the theatre as a learning experience, rather than a purely aesthetic one: 'they can see that others are responding emotionally and so begin to learn appropriate responses themselves' (Kempe, 2014, p.265) and 'through RPs they will learn how to engage in a social and cultural event, not least through experiencing the joint attention it fosters' (ibid., p.272). Performance thus seems to 
become instrumentalist and future-oriented, perhaps not enjoyable in the moment, but 'for your own good' in terms of development. Few commentators describe $\mathrm{RP}$ as an enjoyable cultural activity, as they might for theatre for neurotypical audiences.

Additionally, RPs are generally subsidised to reduce ticket prices and in some cases, reflect the smaller audience capacity. This also occurs in other inclusive arts, such as performances for people with dementia, and may be one reason for the apparently instrumentalist view prevalent among programmers and artists alike-the activity becomes outreach rather than another strand of performance, meaning that it must have identifiable public benefit. Therefore, claims about socialisation and the associated publicity around positive experiences are placed at the forefront, situating people with autism as beneficiaries of culture rather than consumers. As Tony Heaton has provocatively queried, 'it could be argued that we are achieving partial access, but is this potentially more disempowering?' (2013, p.3).

It is interesting to note that a small number of relaxed performances do not focus on theatregoers with additional support needs, but instead are described as 'baby-friendly performances' (Gardner, 2013). As noted above, these productions tend to make small changes to the audience experience to allow them to attend mainstream theatre, in this case, making allowances for the presence of babies, such as permitting theatregoers to leave and re-enter, to feed and to make a degree of noise, mirroring parent-andbaby cinema screenings. The atmosphere remains nonjudgmental, but there are none of the instrumentalist overtones of performances for people with autism. These productions simply allow adults to enjoy the arts while making allowances for their caring responsibilities. 
The explicit right of autistic people to access theatre is enshrined in Article 30 of the United Nations Convention on the Rights of Persons with Disabilities, which states that they should 'enjoy access to television programmes, films, theatre and other cultural activities, in accessible formats; enjoy access to places for cultural performances or services, such as theatres' (United Nations, 2006). Yet the right to withdraw, whether from culture or from community as a whole, is not granted: as has been proposed in relation to children's rights, 'arguably, the absence... of the right not to participate in culture may trouble the entire document' (Fletcher-Watson, 2015, p.28). It should also be noted that 'not everyone agrees that effort should be made to help people access the community-some self-advocacy groups maintain that people with autism should be "allowed" to isolate themselves and abstain from social inclusion if they wish' (Roberts, Beadle-Brown and Youell, 2011, p.46). For example, Edinburgh-based Lung Ha's Theatre Company have traditionally maintained an 'intellectual disability exclusive' artistic process, deliberately removed from mainstream society in order to guarantee a supportive environment (Hall, 2010, p.54). Consultation with theatregoers extends beyond the decision to attend an event, and must be negotiated constantly and with care throughout any encounter with the arts.

The desires of autistic theatregoers, especially adults, may therefore demand greater representation, from programming decisions made in collaboration with advisors in the autism community to involvement in the creation of new pieces, to participation during a live event. In particular, attending to responses from adults with autism could point towards possibilities for more relaxed performances in adult theatre.

The second question emerges from the liminal status of relaxed performance, which could be said to exist in the 
space between traditional performance and inclusive practice. The atmosphere at an $\mathrm{RP}$ is different from a conventional theatre event, marked by noise, physical movement and visibility of the audience. However, the production on stage appears broadly unaffected by this previously 'inappropriate' behaviour. Kurt Lancaster has discussed Susan Bennett's theories about the creation of theatre etiquette: 'in the seventeenth-century, with the rise of private theatres... the audience as a whole became more segregated from the performance space. Caused in part by higher admission prices, theatre architecture, and so forth, this separation bred a more passive and elite audience' (1997, p.76). Supporting this view of modern theatre design as 'unrelaxed', David Bellwood of Shakespeare's Globe, a replica of an Elizabethan theatre which currently stages RPs, states: 'I would forgive you for thinking that the Globe is already a relaxed environment... the sun (or cloud cover) dictates the light levels within the theatre, and as our actors do not use microphones there is nothing to adjust there (as there would be in a West End musical)' (2013, n.p.).

Performer Jess Thom has explored the concept of 'relaxed venues' (Thom, 2015; Tripney, 2015), moving beyond the potentially marginalising effect of RPs to create theatres which accommodate disadvantaged audiences at every performance. For Thom, this could support inclusion by 'introducing relaxed performances to more people, building and sustaining links with new audiences, and developing confidence about access issues amongst theatre companies' (Thom, 2015, n.p.). It can be argued that such theatres could thus play a role in shifting cultural perceptions of disability, adapting to their patrons rather than expecting them to engage with the semiotic conventions of the mainstream, and taking a more radically inclusive approach which blends audiences with and without additional needs. However, as Edward Hall has noted, shared spaces can serve to reproduce marginalisation rather than challenge it (2010). 
To explore this further, it may be useful to contrast relaxed performance with an associated but distinct mode of performance, that of theatre for people with complex disabilities, such as Blue (2006) by Oily Cart. Both fall under the umbrella term 'non-judgmental performance', and both are attentive to the needs of their audiences, but their conventions differ. Oily Cart's productions are usually short, at between 25 and 40 minutes, while RPs are full-length, often incorporating an interval. Theatre for people with complex disabilities tends to be participatory throughout (Brown, 2012), while RP follows the conventions of the individual production, often following a traditionally nonparticipatory model, such as the Broadway musical. Oily Cart and others develop their work from the outset for an audience with additional needs, meaning that they make each aesthetic decision aware of the requirement for safety, comfort and engagement (Young, 2004), while RP presents existing material in a newly created context. Oily Cart has developed individual practices for accommodating its heterogeneous theatregoers, such as one-on-one performances in swimming pools, or the use of suspended chairs to stimulate kinaesthetic sensations; by contrast, RPs presume a homogeneous audience, providing a swathe of generic inclusive measures (see figure 1) to accommodate the majority of needs. Semiotically, theatre for people with complex disabilities recognises and adapts to its audience's lack of recognition of theatre etiquette, for example by replacing applause with intimate moments of one-on-one interaction; RP retains most theatrical conventions, such as raising curtains, clapping hands ${ }^{6}$ and sitting in rows in an auditorium.

Overall, it appears that performances made specifically for people with autism (as well as drama education and dramatherapy approaches) represent discrete theatrical practices, but the status of $R P$ is less clear. Its distinctiveness may yet develop further as the movement grows and practice becomes codified. However, the on-stage 
element currently retains all the hallmarks of traditional mainstream performance, in keeping with the original inclusive aim of these events. This prompts my third question.

Frontline staff are trained in how to respond to autistic audiences for an RP, but actors are not generally assisted to the same extent. The unusual audience dynamic is undoubtedly noticeable to performers, but there is a lack of research into its impact on their performance. In an interview with BBC News on 19 June 2014, actor Alex Gaumond described his experience of playing Miss Trunchbull in an RP of Matilda The Musical (Royal Shakespeare Company, 2010):

It was such an enriching experience, and some of the reactions you got from those kids were so spot-on. I mean, [during] one of my exits, I was called a 'miserable old bat', which I thought is exactly right, you know. They're getting the story, they're getting it, and yes, they possibly don't have that sort of self-censorship to suppress what they feel, or what they want to shout out, and they just shout it out-but they're getting the story (transcribed from Beal, 2014).

Gaumond's pleasure at participating in a RP is evident, yet it is unclear whether the interjections affected his ability to perform. The availability of specific training in theatre for children at institutions such as Rose Bruford College, London, coupled with the long history of courses in Applied Theatre, Theatre in Education, and Drama in Education at UK drama schools, suggests that actors believe they may benefit from education in performance for non-traditional audiences. It also seems likely, as the movement grows, that even actors who choose to work mainly in adult theatre and musicals, as opposed to theatre for children or pantomime, will increasingly be presented with the opportunity to perform in a RP. Until further studies are carried out into 
performance to autistic audiences, it is not possible to determine whether new training is required, but it may be the case that greater understanding could produce autismfriendly acting, as well as autism-friendly audience experiences.

\section{Conclusion}

The tension between instrumentalism and inclusivity continues to problematise the RP movement, most notably in the seeming lack of agency granted to autistic theatregoers beyond the auditorium experience. More research is also needed into the impact on professional performers of participating in RPs, and there may be a need for further training at drama schools and conservatoires as the movement develops.

Several notable features of autism are not currently accommodated by RP practice. In particular, the size of the crowd at larger venues may be off-putting to a significant proportion of the potential audience. New developments in livecasting (streaming live theatre to the web or to cinemas), such as NT Live (NESTA, 2011), may offer a solution to this issue. The combination of a livecast and a relaxed performance could permit patrons who do not welcome the presence of large numbers of strangers to enjoy a specially adapted performance along with those who seek a live theatre experience, albeit with a risk of marginalisation if live broadcasting is used as an alternative to $\mathrm{RP}$ rather than a complement. This model has proved successful in the past-for example, a livecast of Couldn't Care Less (Strange Theatre and Plutôt La Vie) on 18 October 2013 allowed carers for people with dementia to watch the performance from their homes, acknowledging the difficulty they would have encountered in combining a visit to the theatre with their caring responsibilities. 
Alternatively, companies such as Fevered Sleep have begun to experiment with transmedia performance, for example in the app It's the Skin You're Living In (2014), which invites users to collaborate and pool their digital devices in small groups in order to access scenes from a film.

Additionally, mobile apps and digital technology are not yet embedded within arts experiences for autistic people to the same extent as in other domains, such as education or communication. There has been a 'recent explosion in technologies for people with ASD [autism spectrum disorder]' (Fletcher-Watson, S., 2014, p.87), alongside a rise in theatre-derived apps for the general public (FletcherWatson, B., 2014). Significant opportunities exist for the development of autism-specific digital products which may augment live arts events. Notably, Circus Starr, an accessible community circus company, designed their own iOS app to deliver an interactive, personalised storybook as a social story (see figure 1), providing a 'virtual, ring-side circus experience without ever leaving the house' (Logan, 2014). Similarly, Imagination Stage in Maryland has generated social stories in video format, allowing patrons to become familiar with the theatre venue via their computer or mobile device at a time of their choosing (2015).

However, it may also be possible to employ these technologies to permit people with autism to become involved in the evaluation of productions before they are performed, ensuring greater engagement and recognising the importance of involving a target audience at all stages of the development process. Genres such as theatre for Early Years already invite test audiences into rehearsals to gauge responses to work-in-progress (Schneider, 2009), but there are perhaps added ethical and logistical considerations (such as the need for accessible rehearsal spaces) when creating work for the autism community. Furthermore, existing investigative methods tend to rely on observation 
(for younger children), or verbal and pictorial feedback (for older children and adults); these methods may not be appropriate for use with people with autism, whose engagement signals and communication preferences can differ markedly from those of neurotypical theatregoers. A communication interface, combined with video recordings of rehearsed moments, could perhaps cater to their needs while recognising their right to access culture.

It may also be valuable to consider means of extending relaxed practices beyond the current provision of pantomime and children's theatre, to encompass more adult theatre and perhaps other art forms such as opera and ballet. The co-creation of new theatrical experiences with autistic people, possibly through the development of digital interfaces, offers exciting possibilities for the future direction of relaxed performance.

However, for this to occur, a shift in perception of RP seems to be required. Just as theatre for Early Years has moved away from instrumentalist conceptions of teaching 'theatre literacy' in order to produce audiences of the future, and towards an acknowledgement of the right to participate in arts and culture on a child's own terms from birth (FletcherWatson et al., 2014), so perhaps it is time for relaxed performances to be seen as an opportunity for people with autism to enjoy art for its own sake, rather than a form of socialisation imposed by carers. The intrinsic benefits of attending cultural events are significant, but equally, theatre professionals should recognise the right of a person with autism to visit the theatre for pleasure. 


\section{Notes}

1.This paper both uses person-first language ('people with autism') and refers to 'autistic people', in line with mixed preferences in the autism community (Pellicano, Dinsmore and Charman, 2013).

2.Tim Webb of PMLD theatre specialists Oily Cart has provocatively situated them as 'impossible audiences' (Waldron, 2015, n.p.).

3.Makaton is a communication programme which uses signs and symbols to support spoken language.

4.Bree Hadley (2015) has highlighted the impact of the Americans with Disabilities Act (1990) in the USA and the Disability Discrimination Act (1996) in the UK upon theatre venues' requirement to address access, noting that Australia lacks equivalent legislation. This could partially explain the relative paucity of RPs in Australia. However, it should also be noted that the data collection for this study is by necessity Anglo-centric, and does not imply the movement has not spread to Asia, Africa or South America. Nonetheless, personal communications from autism and theatre professionals in Japan, Argentina, Italy, Finland, Norway and the Netherlands indicate no awareness of an emerging autism-friendly mainstream theatre movement in those countries. Internationally-coordinated research could begin to overcome the limitation of reliance on Anglo-centric terminology.

5.'Neurotypical', also NT, is a term which has emerged from within the neurodiversity movement to describe people who are not on the autism spectrum.

6.Although some visitors at the RPs I have attended chose to employ the BSL sign for applause, this was not explicitly requested by any company or venue, despite the potential for overstimulation of hypersensitive individuals of loud clapping.

\section{References}

Ambassador Theatre Group, Society of London Theatre, Theatrical Management Association and The Prince's Foundation for Children \& the Arts, 2013. Relaxed performance project conference: executive summary. [online] London. Available at: 〈http://www.solt.co.uk/downloads/pdfs/pubs/RP\%20-\%20Executive \%20Summary.pdf $>$ [Accessed 8 January 2014]. 
Andrews, L. and Begley, J., 2014. Show time: a guide to creating amazing relaxed performances for people with autism. Birmingham: Autism West Midlands.

Beadle-Brown, J. and Mills, R., 2010. Understanding and supporting children and adults on the autism spectrum. Brighton: Pavilion Publishing.

Beadle-Brown, J., Roberts, R. and Mills, R., 2009. Person-centred approaches to supporting children and adults with autism spectrum disorders. Tizard Learning Disability Review, 14(3), pp.18-26. http://dx.doi.org/10.1108/13595474200900024.

Beal, T., 2014. The RSC stage a 'relaxed performance' of Matilda The Musical. London: BBC News. 19 Jun. Available at: $\langle$ http://www.bbc.co.uk/news/entertainment-arts-27856845 $\rangle$ [Accessed 12 January 2015].

Belloli, J., Morris, L. and Phinney, S. eds., 2013. Small size annual book 3: 2012-13. Bologna: Edizioni Pendragon.

Bellwood, D., 2013. 'Relaxed performance' of Playing Shakespeare with Deutsche Bank: Romeo and Juliet. Shakespeare's Globe Blog. Available at: 〈http://blog.shakespearesglobe.com/post/90658621173/relaxedperformance-of-playing-shakespeare-with $>$ [Accessed 11 January 2015].

Booth, H., 2013. Theatre shows autistic children can enjoy. The Guardian. [online] 25 May. Available at:

〈http://www.theguardian.com/lifeandstyle/2013/may/25/theatreshows-autistic-children $>$ [Accessed 8 January 2015].

Broach, S., Camgöz, Ş., Heather, C., Owen, G., Potter, D. and Prior, A., 2003. Autism: rights in reality: how people with autism spectrum disorders and their families are still missing out on their rights. London: National Autistic Society.

Brown, M. ed., 2012. Oily Cart: all sorts of theatre for all sorts of kids. Stoke on Trent: Trentham Books. http://dx.doi.org/10.1080/08929092.2013.779886.

Carey, B., 2014. Tailoring a play for the acutely attuned: an autisticfriendly version of 'The Curious Incident'. The New York Times. [online] 5 December. Available at: 〈http://www.nytimes.com/2014/12/06/arts/an-autistic-friendlyversion-of-the-curious-incident.html $>$ [Accessed 4 January 2015]. 
Corbett, B.A., Swain, D.M., Coke, C., Simon, D., Newsom, C., HouchinsJuarez, N., Jenson, A., Wang, L. and Song, Y., 2014. Improvement in social deficits in autism spectrum disorders using a theatre-based, peer-mediated intervention. Autism Research, 7(1), pp.4-16. http://dx.doi.org/10.1002/aur.1341.

Costa, M., 2015. It's time for audiences to be less uptight. The Guardian. [online] 4 Mar. Available at: 〈http://www.theguardian.com/stage/theatreblog/2015/mar/04/relaxe d-performances-theatre-time-audiences-less-uptight $\rangle$ [Accessed 4 March 2015].

Didcock, B., 2014. MSP call for autism-friendly pantos. The Herald. [online] 22 December. Available at: 〈http://www.heraldscotland.com/news/health/msp-call-for-autismfriendly-pantos.115005205> [Accessed 12 May 2015].

Elkin, S., 2014. Theatre and autistic spectrum disorders. The Stage. Available at: 〈https://www.thestage.co.uk/opinion/2014/theatreautistic-spectrum-disorders/> [Accessed 12 May 2015].

Elkin, S., 2015. No one else wants to ask this question, so I will. The Stage. Available at: 〈https://www.thestage.co.uk/opinion/2015/susanelkin-no-one-else-wants-to-ask-this-question-so-i-will/> [Accessed 7 April 2015].

Fevered Sleep, 2014. It's The Skin You're Living In. [en] Fevered Sleep. Available at: 〈https://itunes.apple.com/gb/app/its-the-skin-youreliving-in/id788610144 $>$ [Accessed 28 April 2015].

Fletcher-Watson, B., 2014. From stage to screen: adapting a children's theatre production into a digital toy. The Scottish Journal of Performance, 1(2), pp.37-62. http://dx.doi.org/10.14439/sjop.2014.0102.04.

Fletcher-Watson, B., 2015. Seen and not heard: participation as tyranny in theatre for Early Years. Research in Drama Education: The Journal of Applied Theatre and Performance, 20(1), pp.24-38. http://dx.doi.org/10.1080/13569783.2014.953470.

Fletcher-Watson, B. and Fletcher-Watson, S., 2013. Making performances relaxed or autism-friendly. The TYA Blog. Available at: 〈http://tyablog.com/2013/10/21/making-performances-relaxed-orautism-friendly/> [Accessed 11 January 2015].

Fletcher-Watson, B., Fletcher-Watson, S., McNaughton, M.-J. and Birch, A., 2014. From cradle to stage: how Early Years performing arts experiences are tailored to the developmental capabilities of babies 
and toddlers. Youth Theatre Journal, 28(2), pp.130-146.

http://dx.doi.org/10.1080/08929092.2014.940075.

Fletcher-Watson, S., 2014. A targeted review of computer-assisted learning for people with autism spectrum disorder: towards a consistent methodology. Review Journal of Autism and Developmental Disorders, 1(2), pp.87-100.

http://dx.doi.org/10.1007/s40489-013-0003-4.

Frith, U., 2003. Autism: explaining the enigma. 2nd ed. Oxford: Blackwell Publishing.

Gallagher, A., 2015. 'The Lion King' and I. The Huffington Post UK. Available at: $\langle$ http://www.huffingtonpost.co.uk/angela-gallagher-/thelion-king-and-i_b_7034096.html $\rangle$ [Accessed 14 April 2015].

Gardner, L., 2013. Theatre trips for parents should be child's play. The Guardian. [online] 21 March. Available at:

〈http://www.theguardian.com/stage/theatreblog/2013/mar/21/theatr e-for-parents-child-babies $>$ [Accessed 18 July 2014].

Godfrey, E. and Haythorne, D., 2013. Benefits of dramatherapy for autism spectrum disorder: a qualitative analysis of feedback from parents and teachers of clients attending Roundabout dramatherapy sessions in schools. Dramatherapy, 35(1), pp.20-28.

http://dx.doi.org/10.1080/02630672.2013.773131.

Hadley, B., 2015. Participation, politics and provocations: people with disabilities as non-conciliatory audiences. Participations: the Journal of Audience \& Reception Studies, 12(1), pp.154-174.

Hall, E., 2010. Spaces of social inclusion and belonging for people with intellectual disabilities. Journal of Intellectual Disability Research, 54(1), pp.48-57. http://dx.doi.org/10.1111/j.1365-2788.2009.01237.x.

Halpern, E., 2015. The curious incidence of theatre on the autism spectrum. American Theatre. Available at:

〈http://www.americantheatre.org/2015/05/04/the-curious-incidenceof-theatre-on-the-autism-spectrum/> [Accessed 7 May 2015].

Heaton, T., 2013. Access. In: C. Cameron, ed., Disability studies: a student's guide. London: SAGE Publications Ltd, pp.1-3.

Kempe, A., 2014. Developing social skills in autistic children through 'relaxed performances'. Support for Learning, 29(3), pp.261-274. http://dx.doi.org/10.1111/1467-9604.12062. 
Kempe, A.J., 2015. Widening participation in theatre through 'relaxed performances'. New Theatre Quarterly, 31(1), pp.59-69.

http://dx.doi.org/10.1017/s0266464x15000068.

Kuppers, P., 2008. Dancing autism: 'The Curious Incident of the Dog in the Nighttime' and 'Bedlam'. Text and Performance Quarterly, 28(1-2), pp.192-205. http://dx.doi.org/10.1080/10462930701754465.

Lancaster, K., 1997. When spectators become performers: contemporary performance-entertainments meet the needs of an 'unsettled' audience. The Journal of Popular Culture, 30(4), pp.75-88. http://dx.doi.org/10.1111/j.0022-3840.1997.3004_75.x.

Lewis, J. and Banerjee, S., 2013. An investigation of the therapeutic potential of stories in Dramatherapy with young people with autistic spectrum disorder. Dramatherapy, 35(1), pp.29-42. http://dx.doi.org/10.1080/02630672.2013.772456.

Logan, C., 2014. How we made the Show and Tell circus app for children with autism. The Guardian. [online] 26 September. Available at: 〈http://www.theguardian.com/culture-professionalsnetwork/culture-professionals-blog/2014/sep/26/show-and-tellcircus-app-autism> [Accessed 6 January 2015].

Merrill, J., 2014. Pantomime leads the pack in quest to entertain autistic theatre-goers. The Independent. [online] 22 December. Available at: 〈http://www.independent.co.uk/artsentertainment/theatre-dance/news/pantomime-leads-the-pack-inquest-to-entertain-autistic-theatregoers-9939139.html> [Accessed 12 May 2015].

Nerattini, F., ed., 2009. Theatre and Early Years: stories of artistic practice. Small size papers. Bologna: Edizioni Pendragon.

NESTA, 2011. Digital broadcast of theatre: learning from the pilot season of NT Live. London: National Endowment for Science, Technology and the Arts.

Pellicano, L., Dinsmore, A. and Charman, T., 2013. A future made together: shaping autism research in the UK. [online] London: Centre for Research in Autism and Education (CRAE). Available at: 〈http://eprints.ioe.ac.uk/17703/1/A_Future_Made_Together_1.2_LR.pdf〉 [Accessed 12 January 2015].

Ramamoorthi, P. and Nelson, A., 2011. Drama education for individuals on the autism spectrum. In: S. Schonmann, ed., Key concepts in theatre/drama education. Rotterdam: Sense Publishers, pp.177-181. http://dx.doi.org/10.1007/978-94-6091-332-7_29. 
Roberts, R., Beadle-Brown, J. and Youell, D., 2011. Promoting social inclusion for children and adults on the autism spectrum-reflections on policy and practice. Tizard Learning Disability Review, 16(4), pp.45-52. http://dx.doi.org/10.1108/13595471111172840.

Roundhouse (@RoundhouseLDN), 2015. 'Are you coming to our \#ExtraLive, \#NotUptight, \#RelaxedPerformance of @Circolombia on 2 May? http://rhou.se/1DOc3Ty'. 25 April, 10:45 p.m. Tweet.

Rubin, G., 2013. 'Relaxed' theatre performances will let autistic children enjoy hit shows. The Observer. [online] 16 June. Available at: 〈http://www.theguardian.com/society/2013/jun/16/relaxed-theatreautistic-children> [Accessed 8 January 2015].

Schneider, W. ed., 2009. Theatre for Early Years: research in performing arts for children from birth to three. Kinder-, Schul- und Jugendtheater. Frankfurt: Peter Lang.

Sherratt, D. and Peter, M., 2002. Developing play and drama in children with autistic spectrum disorders. Abingdon: David Fulton Publishers. http://dx.doi.org/10.4324/9780203461792.

Social story: Imagination Stage sensory-friendly performances. 2015. Bethesda, MD. Available at: 〈https://www.youtube.com/watch? $\underline{\left.\mathrm{v}=\_Q 9 \mathrm{MxfJ} \_\mathrm{OQC}\right\rangle}$ [Accessed $\left.12 \mathrm{May} 2015\right]$.

Stern, J., 2013. Oxford Playhouse presents 'autism-friendly' musical. $B B C$ South Today. Oxford: BBC News. 4 April. Available at: 〈http://www.bbc.co.uk/news/uk-england-oxfordshire-22026841〉 [Accessed 12 January 2015].

Stone, K., 2014. Autism-friendly 'Into the Woods' is new tack for Old Globe. Times of San Diego. [online] 28 July. Available at: 〈http://timesofsandiego.com/arts/2014/07/28/autism-friendly-intothe-woods-is-new-tack-for-old-globe/> [Accessed 12 January 2015].

Thom, J., 2015. 'Relaxed' vs. 'extra live'. Touretteshero. Available at: 〈http://www.touretteshero.com/2015/02/21/\%e2\%80\%98relaxed \%e2\%80\%99-vs-\%e2\%80\%98extra-live\%e2\%80\%99/> [Accessed 12 May 2015].

Thomson, R.G., 1997. Extraordinary bodies: figuring physical disability in American culture and literature. Chichester: Columbia University Press.

Tripney, N., 2015. How theatre is adapting to relaxed performances. The Stage. Available at: 
〈https://www.thestage.co.uk/features/2015/theatre-adapting-relaxedperformances/> [Accessed 12 May 2015].

uktheatre.org, 2011. Autism \& theatre. [online] UK Theatre. Available at: 〈http://www.uktheatre.org/autismandtheatre.aspx $\rangle$ [Accessed 14 May 2015].

United Nations, 2006. UN Convention on the rights of persons with disabilities. [online] Available at: 〈http://www.un.org/disabilities/convention/conventionfull.shtml〉 [Accessed 18 May 2015].

Viswanathan, V., 2015. Making theater autism-friendly. [online] The Atlantic. Available at:

〈http://www.theatlantic.com/health/archive/2015/04/making-theaterautism-friendly/388348/> [Accessed 7 April 2015].

Waldron, A., 2015. Oily Carted: an interview with Tim Webb. The TYA Blog. Available at: 〈http://tyablog.com/2015/05/08/oily-carted-aninterview-with-tim-webb/> [Accessed 14 May 2015].

Wing, L. and Gould, J., 1979. Severe impairments of social interaction and associated abnormalities in children: epidemiology and classification. Journal of Autism and Developmental Disorders, 9(1), pp.11-29. http://dx.doi.org/10.1007/bf01531288.

Wise, B., 2015. Arts groups offer 'sensory-friendly' events for people with autism. WQXR. Available at: 〈http://www.wqxr.org/story/artsgroups-offer-sensory-friendly-performances-people-autism/? utm_source=sharedUrl\&utm_medium=metatag\&utm_campaign=shar

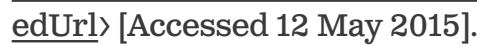

Young, S., 2004. It's a bit like flying: developing participatory theatre with the under-twos: a case study of Oily Cart. Research in Drama Education, 9(1), pp.13-28. http://dx.doi.org/10.1080/1356978042000185885. 


\section{About the author}

BEN FLETCHER-WATSON is currently completing a PhD in drama at the Royal Conservatoire of Scotland and the University of St Andrews, supported by an ESRC CASE Studentship. His research examines contemporary Scottish practice in theatre for early years. He has published articles in journals including Youth Theatre Journal and Research in Drama Education. He serves on the Executive of the Theatre and Performance Research Association (TaPRA) and is an ASSITEJ Next Generation Artist. 